\title{
Porto Alegre: a perdida cidade una (Fragmentos de modernidade e exclusão social no Sul do Brasil)
}

Resumo: O texto compreende uma discussão sobre o processo de modernização na cidade de Porto Alegre em vários momentos de sua história, articulando as transformações e modificações havidas no espaço urbano com uma paralela segregação social operada e/ou desejada na cidade. São recolhidos vários exemplos para demonstrar a vontade de se construir uma "cidade una", na qual não se admite o convívio com os indesejados sociais. A combinação modernização/exclusão social, tantas vezes já abordada em diversos estudos da historiografia brasileira, encontra neste artigo mais um exercício de aproximação, a partir do qual pode-se vislumbrar momentos distintos - sem traçar uma linha de continuidade - desta operação específica da modernidade.

Abstract: The text discusses the process of modernization in the city of Porto Alegre during various moments of its history, debating both transformations and modifications in the city's urban space along with a social segregation that was either going on or being wished for at that time. Many exemples are given so as to demonstrate the desire to build a "united city" in which those who were socially unwished were not allowed. The combination of modernization with social exclusion, so often discussed in many other studies of Brazilian history, is shown in this article as another approach to the issue of modernization with its distinct moments.

Palavras-chave: Rio Grande do Sul. Séculos XIX e XX. Identidade.

Key words: Rio Grande do Sul. XIX \& XX centuries. Identity.

* Este ensaio foi escrito originalmente como avaliação de um Seminário sobre Identidade Nacional na América Latina, dirigido pela profa. Dra. Susana Bleil de Souza no Curso de Doutorado do PPG em História da UFRGS, no primeiro semestre de 1998. O mesmo texto foi apresentado na Mesa de Comunicações Livres "Práticas de Exclusão", durante o IV Encontro Estadual de História promovido pela ANPUH-RS, na UNISINOS, em outubro de 1998.

** Doutor em História pela UFRGS. Professor da UNISINOS. Endereço eletrônico: elmir@bage.unisinos.br

Estudos Ibero-Americanos. PUCRS, v. XXX, n. 2, p. 105-119, dezembro 2004 
"Não pertencer a nenhum lugar; nenhum tempo, nenhum amor. A origem perdida, o enraizamento impossível, a memória imergente, o presente em suspenso. $\mathrm{O}$ espaço do estrangeiro é um trem em marcha, um avião em pleno ar, a própria transição que exclui a parada" (Júlia Kristeva).

Muito se tem falado das controvertidas relações do Rio Grande do Sul com o Brasil ao longo da história. Ao se articular os nexos entre o regional e o nacional, especialmente desde o ponto de vista endógeno da região - quer dizer, o discurso enunciado a partir do estado gaúcho-, são salientados os pontos de atrito e de ruptura com a nação inventada. Um dos eixos centrais que conduzem este debate certamente é a afirmação das diferenças, no intuito de as utilizar na construção de identidades particulares (cf. Oliven, 1992, p. 16).

No campo historiográfico, este debate assumiu um estatuto particular no momento em que foram produzidos trabalhos acadêmicos - especialmente teses de doutorado - cujo locus de análise era o estado do Rio Grande do Sul. Na década de 1980, fez-se ver que na própria conformação do discurso historiográfico nacional deixava-se de considerar as peculiaridades que davam sentido à formação social gaúcha e que ficavam subsumidas numa pretensa história nacional que, na verdade, diluía as diferenças do devir histórico em generalizações cujo ponto de apoio empírico circunscrevia-se a informações restritas ao sudeste brasileiro.

Tributária desta discussão, nos anos 90, quando o foco de análise desloca-se, de certa forma, para a cidade de Porto Alegre, observa-se um aprofundamento desta relativização das circunstâncias históricas. Inúmeras dissertações de mestrado - produzidas especialmente na PUCRS e na UFRGS - dão conta de temáticas relacionadas, de uma ou de outra forma, ao processo de modernização da cidade de Porto Alegre na conjuntura entre o final dos oitocentos e a primeira metade do século XX.

Não é meu objetivo realizar um inventário destes trabalhos, mas partir desta constatação para empreender um exercício de análise histórica. A questão que me proponho perseguir refere-se ao duplo modernização/exclusão social. Assim como "a consciência da modernidade nasce do sentimento de ruptura com o passado" (Le Goff, 1985, p. 371), é possível dizer que as transformações objetivas e subjetivas que podem ser constatadas ao longo da história de Porto Alegre, especialmente a partir da segunda metade do século XIX, são associadas à cisão de um tempo e, no mesmo movimento, à constituição de uma nova temporalidade. 
A coexistência de opostos, ou do dual, neste processo é uma constatação recorrente. Afirma-se a transformação para associá-la ao "bom" ou ao "ruim". Realiza-se um jogo de oposições sucessivas a fim de assinalar, quase sempre, a precariedade do tempo presente.

Este artigo pretende discutir a idéia de que, em várias ocasiões, a cidade de Porto Alegre serviu de inspiração espacial para a afirmação da experiência de ruína ou de queda. Sentimentos pessimistas quanto ao presente ou ao futuro, contrapostos a um idílico passado, reforçaram esta concepção. Com isto, esboça-se em várias falas e desde diversos pontos de enunciação - jornalístico, literário, político... - a idéia da existência de uma "cidade perdida", esteja esta associada ao "mundo das idéias" ou ao "mundo dos fatos" - embora saibamos que uma rigorosa separação destes termos é inócua.

No meu ponto de vista, a perda da "cidade una" está intrinsecamente ligada a um processo de "desidentidade imaginária" operado ao longo dos anos em Porto Alegre. Ao mesmo tempo, este processo vincula-se aos próprios atores sociais - cada vez mais diversificados - que desestabilizam a previsibilidade de um jogo social desejado. Assim, a exclusão social - imposta desde outrem ou auto-instituída - reitera a premissa da "cidade perdida" e, paralelamente, constitui-se numa tentativa de homogeneizar o espaço da diferença para reafirmar e reinstituir um igual originário, mais utópico do que plausível.

Desta forma, este ensaio pretende analisar uma relação paradoxal existente no seio da cidade: as formas pelas quais a sua enunciação elabora o desejo da "cidade una" (cf. Loraux, 1993, p. 75-97). O paradoxo reside justamente no fato de a linguagem, que é um dos lugares privilegiados do conflito (cf. Brandão, 1991, p. 12), fundar um discurso que prescreve a coesão.

A cidade de Porto Alegre, ao longo de sua história, tem muitos exemplos deste desejo. Podemos pensar que o conflito faz parte do jogo político que erige a cidade enquanto tal, mas um olhar mais detido sobre a conformação social da mesma faz perceber que é o "igual" o elemento que movimenta um pensamento conservador recorrentemente em cena. Com isto, temos um par de duplos a marcar as visões sobre a cidade: o universo político movido pelo reconhecimento do desigual (especialmente no período entre 1946 e 1964), e o universo social entendido como uno.

Não é difícil chegar a esta constatação quando analisamos a história e a historiografia da cidade. Aqueles que escreveram ou escrevem sobre a cidade assumem duas posições: ou reproduzem esta concepção da "cidade una" no seu discurso, ou realizam a sua existência através das fontes que utilizam em seus trabalhos. 
Quero demonstrar, através de alguns exemplos recolhidos de maneira quase aleatória, a configuração deste desejo. Penso que é possível concluir, a partir deles, este jogo de palavras que, ao eleger um "unitário ideal" perdido num tempo que não é o nosso, encontra no tempo presente os sintomas de sua ausência, como já referi anteriormente.

Quanto mais examinamos o universo, afirma Joseph de Maistre, mais nos sentimos levados a crer que o mal vem de uma certa divisão que não sabemos explicar, e que o retorno do bem depende de uma força contrária, que nos impele sem cessar para uma certa unidade igualmente inconcebível (apud Girardet, 1987, p. 142).

Trata-se, assim, de um problema trágico, ou seja, destituído de solução. O mito da unidade faz ver que tanto o passado quanto o futuro fogem à capacidade de intervenção do sujeito, sendo o presente o tempo da queda, da desfiguração, da ruína, enfim, de tudo aquilo que desagrega. Existe um horizonte constantemente evocado como referência do mundo plano e tranqüilo que funciona somente de ancoragem para um pensamento descontente com o "mundo real"; este, turvo e desesperador.

Os exemplos que escolhi para mostrar a invenção de um mundo em queda na capital do Rio Grande do Sul associam os espaços físicos aos espaços sociais e aos atores que os habitam/constituem. A cidade de Porto Alegre, no mesmo passo em que vê modificar-se a sua configuração territorial ao longo dos anos, recuando a sua área em quilômetros quadrados na medida em que novos municípios são criados, também opera a movimentação de seus habitantes, para ratificar a inclusão de alguns e para estabelecer a exclusão de outros.

Com isto, é a morte da contradição o processo que se observa em Porto Alegre, ao serem criados territórios apartados da cidade política (pólis). Isto, no caso de reconhecermos no campo político a premissa da existência de "discursos duplos" (dissoi logoi), o que certamente não pode ser dito para a história política da cidade de Porto Alegre em toda a sua extensão. Ao longo de sua trajetória histórica, Porto Alegre vê surgir espaços cuja finalidade de criação reside justamente no desejo da separação da mistura que pode trazer de volta a unidade perdida.

Limites, barreiras, fronteiras físicas foram a solução mais imediata que, contudo, utilizava a incorporação, por parte do excluído, da racionalização feita pela sua diversidade, no seio de uma estratégia classificatória e discriminatória virada para a organização e o controlo dos fenômenos, através da sua separação e parcelamento (Basaglia, 1994, p. 355). 
Temos, assim, um processo interdependente: ao mesmo tempo em que se exclui o diverso do "centro" - daquilo que os gregos antigos denominavam és méson - (cf. Detienne, 1989, p. 46-53), articula-se a inclusão do mesmo num espaço de margem, de limite, longe da vista dos "iguais".

Este é o caso, por exemplo, das instituições penitenciárias em Porto Alegre. A Casa de Correção, construída entre 1825 e 1855, às margens do Guaíba e ao lado da Usina do Gasômetro, é dinamitada em 1962, quando se inaugura o Presídio Central de Porto Alegre (Franco, 1988, p. 90 e 124-125). Se o incêndio ocorrido naquela casa em 1954 e toda uma discussão verificada na imprensa local, nas casas legislativas e na Justiça condenando a situação de abandono daquele estabelecimento, foram fundamentais para esta decisão (cf. Elmir, 2001, p. 295-299), não podemos esquecer o significado simbólico desta transferência de local. A Casa de Correção localizava-se no centro da cidade, em uma via movimentada, a poucos metros dos principais órgãos públicos do estado e do município, da principal saída rodoviária de Porto Alegre e do porto da cidade. Assim, não é apenas o cuidado com as condições de vida do apenado e a preocupação com a promiscuidade o que explica a necessidade de retirá-lo daquele espaço.

O desejo de esconder do olhar cotidiano a casa prisional, afastando-a do centro da cidade, e a necessidade de dificultar tentativas de fuga por via fluvial ou mesmo terrestre, também movem o poder público a construir um novo Presídio Central num bairro de periferia da cidade. Longe do porto - símbolo de liberdade e movimento-, a casa do Partenon cumpre o papel de duplicar a segregação dos criminosos, ao colocá-los à margem da cidade, mais próximos do extrato social da população de onde a maior parte dos "bandidos" provém, e no caminho de Viamão.

Mais de trinta anos depois da transferência, discute-se novamente a desativação do presídio. O motim e a fuga ocorridos no inverno de 1994, cuja repercussão nos meios de comunicação foi enorme (cf. Elmir, 2004), certamente estão na origem deste debate. O governador do estado e o secretário da segurança pública em 1995 falavam em desativar aquele estabelecimento, vender o prédio e transferir os presos para outras casas prisionais na região metropolitana de Porto Alegre. Novamente, a existência de maior número de apenados que a capacidade prevista comporta - cerca de três vezes o número de vagas - constitui o argumento fundamental para esta "descentralização" do sistema. 
Não obstante, é preciso também lembrar que a cidade de 1994 não é a mesma de 1954/1962, e que o bairro Partenon, antes considerado periferia da capital, hoje constitui plenamente a zona urbana de Porto Alegre. É interessante observar que moram nas adjacências do Presídio Central do Partenon membros da Brigada Militar; desde o referido motim, instituição responsável pela administração daquele estabelecimento. Há poucos metros do presídio também existem artérias que foram habitadas, em grande parte, depois da construção do presídio, onde se encontram belas residências, quase todas construídas a partir dos anos 80. Assim, o presídio encontra-se numa área que se diversifica e cresce e que, por isto, paradoxalmente, não pode admitir a mistura com os representantes do impuro.

O "centro", ao avançar para os bairros, institui novas margens e a periferia já não são os "arrabaldes afastados", mas as cidades que se desenvolveram nas fronteiras da capital especialmente a partir dos anos 50 (Canoas, Cachoeirinha, Alvorada, Gravataí...). É para estes outros centros urbanos que o governo gostaria de estar enviando os apenados, através de projetos de construção de presídios menores, garantindo com isto a fragmentação de sua identidade e, ao mesmo tempo, a (re)criação da cidade una. As populações destes municípios e seus representantes têm se manifestado contra esta nova "mistura social", associando a presença dos presos à formação de um estigma/vergonha, sem falar da assunção de um medo premonitório por parte destas comunidades.

Coincidentemente, é para a mesma região que os "loucos" da cidade foram enviados no final do século XIX, quando da inauguração do Hospício São Pedro, em 1884, na então Estrada do Mato Grosso (hoje, avenida Bento Gonçalves), no mesmo bairro Partenon. Retiram-se os pacientes da Santa Casa de Misericórdia e da Casa de Correção, instituições localizadas no centro da cidade, "guardando-os" longe das vistas e dos ouvidos das famílias sadias da capital.

Paradoxalmente, é a construção daquele hospital um dos elementos responsáveis pelo próprio crescimento do bairro Partenon, como demonstra o historiador Sérgio da Costa Franco:

[...] a 11/04/1895, outra companhia de bondes de tração animal, a Carris Urbanos, levaria seus "caixas de fósforo" até o Partenon, seguindo, a partir da Rua dos Andradas, Caminho do Bom Fim, das ruas Venâncio Aires e Santana, até a Praça Jaime Teles, e daí pela hodierna Av. Bento Gonçalves, com fim de linha no Hospital São Pedro (Franco, 1988, p. 310). 
Vemos assim que a intenção de segregar, separar ou afastar o "diferente" do convívio dos "iguais" é traída por uma lógica de modernização da cidade que exige a expansão do seu espaço físico através da integração de suas várias regiões. Podemos dizer, desta forma, que não existe um processo unívoco de exclusão, mas um embate contínuo entre forças centrífugas e centrípetas do qual resulta a conformação social e territorial da cidade.

Numa conjuntura imediatamente anterior à discussão da necessidade da construção de um espaço específico para gerir a loucura, cria-se um cemitério na periferia da cidade, em substituição ao Cemitério da Igreja Matriz, que desde 1772 comportava os sepultamentos dos porto-alegrenses. Novamente, temos o desejo de criar uma cidade apartada, agora para os mortos, a fim de manter a unidade de uma cidade habitada por homens vivos. Ao se verificar o crescimento do centro, formulam-se preocupações com a saúde pública. Com isto, escolhe-se os altos da Azenha (Av. Oscar Pereira) para localizar o novo campo santo (Franco, 1988, p. 109-111).

Ainda no século XIX, temos testemunhos de viajantes estrangeiros que flagram momentos diferentes de Porto Alegre e que nos fazem perceber o quanto a cidade cresce, quer para se fazer uma só, quer para gerar a própria diversidade contra a qual alguns homens pretensamente ilustrados lutam. O francês Nicolau Dreys, em 1839, afirmava que "...há pouco mais de 60 anos que o lugar, em que se levanta essa suntuosa cidade, era selvagem, coberto de matos, asilo ordinário de feras" (Dreys, 1990, p.66). A partir desta impressão devemos questionar se a preeminência da origem lusitana na definição populacional dos primórdios de Porto Alegre e o orgulho que decorre deste começo não constituem um dos mitos de unidade aos quais se recorre quando o tempo presente assusta aqueles que temem um social múltiplo e difuso. As precárias chegada e instalação dos primeiros açorianos à cidade, em meados dos setecentos, através de sua reconfiguração discursiva no romance de Luiz Antonio de Assis Brasil (Um quarto de légua em quadro), convenientemente ajuda a desfazer a pintura retocada de um início sublime.

Ao lermos a descrição que Joseph Hörmeyer (1856) faz de Porto Alegre alguns anos depois de Dreys damo-nos conta de que a mistura social e étnica é um dos princípios a definir a vida na urbe (cf. Elmir, 1990, p. 95-103). A constatação da existência de escravos de ganho nas ruas da cidade convivendo com os homens brancos aponta para a necessidade de se reconhecer uma sociedade em processo de constituição. Em outros termos, é impossível localizar em Porto Alegre o locus de uma formação social cristalizada e impermeável a múltiplas determinações. O século XIX cer- 
tamente é o momento privilegiado da percepção de uma ordenação social cujas relações interétnicas são um imperativo de sobrevivência dos vários grupos e também uma premissa para o próprio "fazer-se" do futuro porto-alegrense.

Avançando no século XX, cerca de cem anos depois de Hörmeyer ter visitado Porto Alegre, Érico Veríssimo publica o romance Noite (1954), no qual se destaca como personagem um homem deslocado e atormentado na cidade; uma "cidade estrangeira". O sentimento de perda pessoal naquele território estranho justapõe, no plano ficcional, a premissa da perda da unidade da cidade que vem sendo desdobrada neste texto: "Olhou em torno e não reconheceu nada nem ninguém. Estava perdido numa cidade que jamais vira. [...] Quem sou? Onde estou? Que aconteceu?" (Veríssimo, 1980, p. 1-2).

O pessimismo, a identidade partida, a solidão são elementos recorrentes na narrativa e que nos desafiam perigosamente a sobrepor a "cidade estrangeira" de Veríssimo à Porto Alegre perdida de nosso texto. A modernidade porto-alegrense dos "anos dourados" não era muito diferente daquela do narrador de Veríssimo (cf. Elmir, 2002), quando este diz: "Você já deve ter reparado como a mocidade de hoje se entrega desesperadamente à vida vertiginosa, à velocidade, à bebida, numa palavra: à dissipação, como diria um moralista" (Veríssimo, 1980, p. 87).

Ao mesmo tempo, os tipos que circulam na "Noite" de Veríssimo guardam semelhança com a experiência mesma da modernidade, na forma como Marshall Berman a define, ou seja, como uma experiência que "...anula todas as fronteiras geográficas e raciais, de classe e nacionalidade, de religião e ideologia" (Berman, 1989, p. 15). Diz um dos freqüentadores de um cabaré:

- Veja essa gente - disse. - Aqui temos de tudo. Moços e velhos, casados e solteiros. Filhos de famílias da alta burguesia e empregadinhos do comércio. Está vendo aquela rapariga bonita, de olhos grandes e pinta na face? É de uma boa família. Classe média, o pai é aposentado. Ela é empregada pública e ganha pouco. É de noite que faz mais dinheiro. De manhã, naturalmente dorme. Tem um noivo, rapaz do interior, creio que fazendeiro. Vão casar o mês que vem. Alô, meu bem! (Veríssimo, 1980, p. 85-86).

Além de espaço da mistura, a cidade comporta sujeitos de identidades ambíguas. É também no plano moral que se pode fazer restrições à diferenciação ou, ao contrário, apenas constatar a sua existência. Afinal, a modernidade parece se relacionar melhor com os juízos de fato, e não com os de valor. 
Mas se no plano da prosa literária é temerário estabelecer relações diretas com o mundo fático - afinal, como diz um personagem de Veríssimo: "Tudo isto pode ser apenas um sonho e ninguém nunca nos pede contas do que fazemos em sonhos" (Veríssimo, 1980, p. 108) -, já no âmbito do discurso parlamentar e jornalístico espera-se uma verossimilhança maior.

Exatamente nesta mesma conjuntura da publicação do romance de Érico Veríssimo, no legislativo municipal, muito se discute sobre as questões sociais que envolvem uma cidade cuja população já passou do meio milhão de habitantes. O problema da moradia e com ele o do crescimento das sub-habitações na periferia da cidade, com a ocupação de áreas mais afastadas pelos pobres e desempregados é uma questão que preocupa os vereadores de Porto Alegre. Os "menores" e a sua possível trajetória criminosa vinculada à desagregação dos lares, quer seja dos ricos ou de miseráveis, é assunto exaustivamente debatido na Câmara Municipal entre os anos 1950 e 60 (cf. Elmir, 2002).

A prostituição e o atentado que representa para a vida civilizada da cidade é outra matéria de intervenção dos vereadores (cf. Elmir, 2003, p. 218-228). Entre estes, o delegado Célio Marques Fernandes é o maior interessado, inclusive propondo a solução privada da questão, incitando em seus discursos a própria população a resolver pessoalmente esta imoralidade, quando declara tanto a polícia quanto os demais órgãos do poder público incompetentes para efetivar uma solução.

Lembrando a luta pela expulsão das prostitutas da rua Cabo Rocha (atual rua Prof. Freitas e Castro), no bairro Azenha, em 1956, Fernandes demonstra que não é apenas a nefasta influência exercida pelas prostitutas sobre a sociedade a preocupação dos homens públicos da cidade. Havia também o temor do aprofundamento de um processo de indiferenciação social que a mistura vinha engendrando através da disseminação física do meretrício.

Neste sentido, a maciça concentração desta atividade no centro da capital até o final da década de 1930 deu lugar à constituição de outros centros desde os anos 40 e que na conjuntura que ora tratamos assume uma visibilidade inaceitável quando estes centros são também o espaço de sociabilidade das famílias da periferia e do progresso através de novas construções e atividades econômicas, como é o caso do comércio na Av. Azenha.

Um índice desta mistura, lembrado por Marques Fernandes, é o fato de as meretrizes usarem as mesmas roupas que as mulheres de família envergam, dificultando, assim, a necessidade da distinção pelo erro moral de umas e pela conduta imaculada das 
outras (Anais da Câmara Municipal de Porto Alegre, 09/08/1960, p. 97). Por outro lado, o vereador discorda da prática policial de prender as prostitutas sem motivo e de as levar para a $2^{\mathrm{a}}$ Delegacia de Polícia, a qual não tem estrutura física para recebê-las. Por encontrar-se a delegacia em plena Av. Azenha, novamente as famílias precisam conviver com os gritos, vexames e palavrões pronunciados pelas "decaídas" (Idem, 18/08/1960, p. 146).

Talvez seja possível concluir, a partir da leitura dos Anais da Câmara de Vereadores e dos Anais da Assembléia Legislativa entre o final da década de 50 até a primeira metade dos anos 60, uma imensa politização das questões sociais ligadas ao crescimento da cidade e dos sinais de criminalidade verificados pelos parlamentes, especialmente em Porto Alegre.

Em 1958, um repórter do jornal Diário de Notícias faz uma série de matérias sob o título de "O drama das nossas populações marginais", com a qual ganhou o Prêmio Esso de Jornalismo, para a região sul, na categoria reportagem. Nelas, Ruy Pratini traz alguns números que revelam a dimensão que a questão social assume em Porto Alegre nesta conjuntura.

Pratini fala na existência de 73 mil pessoas vivendo em condições precárias em 33 núcleos de malocas; 30 mil menores abandonados que revelam não apenas a miséria material mas a miséria moral das famílias, com um grande índice de mães solteiras; $62 \%$ de taxa de mortalidade para crianças de até um ano que vivem nestas vilas. Superestimado ou não, certamente este quadro social haveria de ter repercussão nos debates políticos ocorridos nas Casas Legislativas.

E significativo observar no relato quase etnográfico que o repórter faz de sua visita a estas vilas para escrever sua matéria o estranhamento percebido na relação que ele estabeleceu com os moradores locais. Pratini fala da desconfiança desta população, do seu silêncio, talvez do medo que a impedia de falar de sua miséria evidente. A certa altura, relata:

[...] surgiram, então, retalhos de conversas, numa linguagem quase incompreensível. Uma velha bugra (a Paraguaia), com fisionomia que representa a própria máscara da miséria e do sofrimento, perguntava em voz estridente: - Esses "estranja" - donde saíram? - É que todo indivíduo estranho em Mato Sampaio é considerado nada menos do que estrangeiro (Anais da Assembléia Legislativa do Rio Grande do Sul, 03/09/1959, p. 29).

Neste relato jornalístico percebemos como um membro de um setor da sociedade representa uma outra camada desta mesma 
sociedade. São pessoas que vivem na mesma cidade, mas se estranham. Uns pertencem efetivamente à comunidade política, à polis; outros estão nas margens da cidade política e por isto existe o mútuo estranhamento que faz emergir o ser estrangeiro de ambos os grupos sociais.

O jornalista pouco entende a língua desta gente, ainda que estas pessoas vivam no mesmo espaço geográfico cujo território define a cidade de Porto Alegre. O que ocorre na situação descrita é o espanto de reconhecer-se incluído num espaço social de exclusão. O jornalista, os deputados, os vereadores, quando falam da vida na cidade se assustam ao darem-se conta de que a cidade de Porto Alegre não é uma só; é uma cidade plural no pior sentido que possamos atribuir a esta expressão; quer dizer, uma cidade que é capaz de produzir a segregação.

Esta região (o Mato Sampaio), que foi habitada no início da década de 50, através da transferência de famílias que moravam nas Docas das Frutas, Seca, Campo do Pólo, Coréia e Dona Teodora, é denominada por Ary Veiga Sanhudo neste mesmo momento como um "submundo dos arredores da capital", "quase um "país inimigo', ainda que vizinho da cidade", "lugar perdido", "cancro escondido e secreto", "grande vila perdida", "submundo", "subcidade" (Sanhudo, 1975, p. 152-157); expressões que comportam ao mesmo tempo o desprezo e o pavor de um lugar que não se quer reconhecer fazendo parte de Porto Alegre.

A identificação entre o espaço físico degradado e seus habitantes não deixa dúvidas quanto à visão de uma cidade partida, como se de um núcleo celular sadio fossem formadas metástases desagregadoras que só servem para destruir a unidade do corpo. Diz Sanhudo: “...às vezes me convenço mesmo que todo o problema das malocas, em Porto Alegre, reside simplesmente na convulsiva massa humana que as constitui" (Sanhudo, 1975, p. 202). Mesmo segregados, os pobres continuam a incitar no cronista dos bairros e das ruas de Porto Alegre a xenofobia de quem não pode admitir conviver, mesmo à distância, com o diferente. No discurso de Sanhudo, estes sujeitos são feitos apátridas de sua própria cidade, num exercício de mutilação simbólica que elimina qualquer possibilidade de identidade pessoal com o lugar (cf. Giménez, 1993, p. 20).

Jean-Pierre Vernant, ao falar da questão do estrangeiro, diz: "O mesmo só se concebe e só pode definir-se em relação ao Outro, à multiplicidade de outros. Se o mesmo permanece voltado sobre si mesmo, não há pensamento possível" (Vernant, 1988, p.34). O que se pode concluir desta proposição? Alguns podem interpretá- 
la como reveladora da inevitabilidade da diferença e da necessidade de admitir conviver com ela, pois é a alteridade vista na imagem do outro que faz com que nós nos reconheçamos como iguais. Contudo, existe um perigo contido nesta interpretação: o de naturalizarmos a diferença e, a partir disto, desencadearmos um sentimento conformista em relação a uma ordem social claramente injusta. Ao contrário, a realização de que existem estrangeiros entre membros de uma população que nasceu no mesmo território deve nos fazer pensar que sequer o princípio da igualdade liberal foi posto em prática; que existem cidadãos de segunda categoria; que muitos foram excluídos da política porque simplesmente não são capazes de exercê-la porquanto não têm o instrumento de poder por excelência: lógos (a palavra, o discurso) (cf. Vernant, 1984, p. 34 e Ianni, 1986, p. 131).

É no decorrer da década de 1970 até meados dos anos 80 que percebemos claramente a configuração de um discurso modernizador na cidade, pelo qual o interlocutor privilegiado do governo não era mais o cidadão (o sujeito político), mas sim o habitante da cidade, a sua população dissolvida num projeto único de incorporação aos supostos benefícios sociais do Estado (condensado no poder executivo).

A desativação dos bondes, por exemplo, já se dera em 1967, sob o governo de Célio Marques Fernandes. É na administração de Thompson Flores (1969/1975) que houve a proposta malograda de demolir o Mercado Público Municipal (Carneiro; Pena, 1992, p. 161). É também na década de 70 que teremos a construção do viaduto no cruzamento da Av. Borges de Medeiros, Padre Cacique e José de Alencar, assim como será inaugurado o Viaduto Loureiro da Silva, que não por acaso traz o nome de um ex-prefeito da capital famoso por sua administração empreendedora no campo viário (criação e/ou urbanização e saneamento das Av. Farrapos, João Pessoa, André da Rocha, Jerônimo de Ornellas e Ipiranga). É interessante notar que foi coincidentemente sob um regime de exceção (o Estado Novo) que estas obras se realizaram.

Não estou afirmando com isto a identidade necessária entre regimes políticos autoritários e projetos modernizadores. Apenas quero registrar que foram estes projetos uma das estratégias desmobilizadoras levadas a efeito por estes prefeitos; o que também não significa que estas obras fossem necessariamente supérfluas. $\mathrm{O}$ que ocorreu foi uma cisão na unidade cidade/política, tal como este duplo havia se constituído no período político anterior, ou seja, entre 1946 e 1964. 
O que não se queria era uma sociedade tensionada, uma sociedade na qual a disputa, a competição fosse um instrumento legítimo de construção de uma obra coletiva. Nesta perspectiva, a urbanização e o crescimento da cidade não eram obras coletivas, mas o resultado do esforço esclarecido de alguns poucos homens que sabiam o que a cidade precisava.

É significativo neste sentido o texto de uma publicação feita pelo executivo municipal por ocasião da XVIII Semana de Porto Alegre, em meados dos anos 70, ou seja, sob o governo de Guilherme Socias Villela, no qual se faz o elogio de Porto Alegre, das suas belezas naturais, da sua prosperidade econômica, e da sua "gente". Podemos ler sob este tópico:

Incontestavelmente somos uma gente que ama a Paz e que preza a liberdade. Paciente em relação às nossas aspirações e docilmente dedicada ao amanhã. Somos uma gente temperada pelas agruras do dia-a-dia mas ao mesmo tempo alegre e otimista. Somos um milhão de pessoas a contribuir com expressiva cota para o crescimento do país (Porto Alegre. Ed. Edel, s.d., p. 32 e 34).

Ora, o que podemos concluir deste texto oficial do governo de Villela, no qual é definido quem é o porto-alegrense? É paciente, dócil, esforçado, crente nas perspectivas do progresso e do futuro. Este não é apenas o porto-alegrense; este é o homem cordato que a ditadura militar tentou forjar nos 20 anos de governo. As imagens do texto permitem entrever a representação de uma cidade una que não pertence senão à imaginação do discurso político oficial e de seus representantes.

Para concluir este repertório difuso do jogo cidade: unidade/diversidade; modernização/exclusão social, não posso deixar de mencionar, embora de maneira sumária, a campanha que foi feita ao longo de 1998 em Porto Alegre ("Movimento Sinal Vermelho", promovido pela Rede Brasil Sul de Comunicações) contra a caridade nas ruas da cidade, especialmente aquela que responde aos jovens estabelecidos nos cruzamentos das principais artérias que cortam a capital. Estas ruas largas, pavimentadas e bem iluminadas representam e conduzem a modernização da cidade mas, paradoxalmente e ao mesmo tempo, fixam os excluídos deste processo nos seus eixos. Novamente, atenta-se contra a cidade una. Mais uma vez, tenta-se recompô-la.

Luís Fernando Veríssimo produz uma imagem forte desta tragédia urbana em crônica na qual demonstra o sentimento ambíguo e confuso de quem é assaltado pela interpelação destes pequenos estrangeiros que habitam as sinaleiras da cidade: 
O mais terrível não era a menina me chamando de 'tio' e pedindo um trocado, ela de pé no chão do asfalto e eu no meu carro de bacana. O mais terrível não era eu escolhendo a cara e a voz para dizer que não tinha trocado, desculpe, como se a vergonha tivesse um protocolo que a absolvesse. O mais terrível não foi nem a naturalidade com que ela cuspiu na minha cara. O mais terrível foi que ela era tão pequena que a cusparada não me atingiu (Veríssimo, 1994, p. 87).

Os múltiplos inacabados que envolvem o seu texto, a dissimulação, a comunicação inconclusa e o deslizar de sentidos, representam um pouco a modernidade da cidade. A consciência da exclusão social e a tentativa de esquivar-se de sua percepção apontam para uma atitude ao mesmo tempo cínica e impotente do cronista/narrador. $\mathrm{O}$ estranhamento de um parentesco inventado - $\mathrm{o}$ "tio" - e a esperança de religar estrangeiros inconciliáveis por este mesmo parentesco remetem para as identidades/desidentidades próprias de uma cidade partida. Talvez exista no desfecho desta história - a terrível sensação da cusparada que não atingiu a cara do narrador - a esperança de um projeto de cidade solidária. Mas, o pior de tudo é que, quase sempre, a sinaleira abre e a gente vai embora.

\section{Referências}

ASSIS BRASIL, Luiz Antônio de. Um quarto de légua em quadro. 6. ed. Porto Alegre: Movimento, 1997.

BASAGLIA, F. Ongaro. Exclusão/Integração. In: Enciclopédia Einaudi, v. 23. Inconsciente-Normal/Anormal. Lisboa: Imprensa Nacional/Casa da Moeda, 1994, p. 323-341.

BERMAN, Marshall. Tudo que é sólido desmancha no ar. A aventura da modernidade. São Paulo: Companhia das Letras, 1989.

BRANDÃO, Helena Nagamine. Introdução à análise do discurso. Campinas: Editora da Unicamp, 1991.

DETIENNE, Marcel. Os mestres da verdade na Grécia Arcaica. Rio de Janeiro: Jorge Zahar, 1989.

DREYS, Nicolau. Notícia descritiva da Província do Rio Grande de São Pedro do Sul. 4. ed. Porto Alegre: Nova Dimensão/Edipucrs, 1990.

ELMIR, Cláudio Pereira. O escravo urbano na visão de um viajante. Estudos IberoAmericanos, PUCRS, v. 16, n. 1,2, p. 95-103, jul.-dez. 1990.

Polícia, justiça e imprensa: as disputas para a constituição do campo legítimo para a enunciação do crime. Justiça \& História, Porto Alegre, Tribunal de Justiça do Estado do Rio Grande do Sul, v. 1, n. 1 e 2, jan.-dez. 2001, p. 259-312. 
. A enunciação do limite: os menores e o caminho para a criminalidade. Justiça \& História, Porto Alegre, Tribunal de Justiça do Estado do Rio Grande do Sul, v. 2, n. 3, jan.-jun. 2002, p. 359-398.

. A transgressão do limite: sedução, adultério, prostituição e estupro no Rio Grande do Sul de meados do século XX. Justiça \& História, Porto Alegre, Tribunal de Justiça do Estado do Rio Grande do Sul, v. 3, n. 6, jul.-dez. 2003, p. 199-241.

ELMIR, Cláudio Pereira. Introdução. A noite dos desesperados. In: - $O$ crime da Última Hora. Porto Alegre na passagem dos anos 50. Porto Alegre: UFRGS, 1996. p. 1-15 (Dissertação de mestrado em história).

FRANCO, Sérgio da Costa. Porto Alegre: guia histórico. Porto Alegre: Ed. UFRGS, 1988.

GIMÉNEZ, Gilberto. Apuntes para una teoría de la identidad nacional. Sociológica, año 8, n. 21. Identidad nacional y nacionalismos. Enero-abril de 1993, p. 13-29.

GIRARDET, Raoul. Mitos e mitologias políticas. São Paulo: Companhia das Letras, 1987.

HÖRMEYER, Joseph. O Rio Grande do Sul de 1850. Descrição da Província do Rio Grande do Sul no Brasil Meridional. Porto Alegre: DC Luzzatto/Eduni-Sul, 1986.

IANNI, Octavio. Classe e nação. Petrópolis: Vozes, 1986.

KRISTEVA, Júlia. Estrangeiros para nós mesmos. Rio de Janeiro: Rocco, 1994.

LE GOFF, Jacques. Antigo/Moderno. In: Enciclopédia Einaudi, v. 1. MemóriaHistória. Lisboa: Imprensa Nacional/Casa da Moeda, 1985.

LORAUX, Nicole. A cidade pensa o um e o dois. In: CASSIN, B.; LORAUX, N.; PESCHANSKI, C. Gregos, bárbaros, estrangeiros. A cidade e seus outros. São Paulo: Editora 34, 1993 (p. 75-97).

OLIVEN, Ruben George. A parte e o todo. A diversidade cultural no Brasil-nação. Petrópolis: Vozes, 1992.

PENNA, Rejane; CARNEIRO, Luiz Carlos. Porto Alegre: de aldeia à metrópole. Porto Alegre: Marsiaj Oliveira/Officina da História, 1992.

SANHUDO, Ary Veiga. Porto Alegre: crônicas da minha cidade. Porto Alegre: Movimento, 1975.

VERÍSSIMO, Érico. Noite. 12. ed. Porto Alegre: Globo, 1980.

VERÍSSIMO, Luís Fernando. Traçando Porto Alegre. Porto Alegre: Artes \& Ofícios, 1994.

VERNANT, Jean-Pierre. A morte nos olhos: Figurações do outro na Grécia Antiga. Ártemis e Gogó. Rio de Janeiro: Jorge Zahar, 1988.

VERNANT, Jean-Pierre. As origens do pensamento grego. 4. ed. São Paulo: Difel, 1984. 